\title{
Effect of grain size on the drawability of the niobium-stabilized ferritic stainless steel ASTM 430
}

\author{
Caio César Caldeira Moura ${ }^{1 *}$ \\ Reginaldo Pinto Barbosa ${ }^{1}$ \\ Tarcísio Reis de Oliveira ${ }^{1}$
}

\begin{abstract}
Studies were carried out with samples of AISI 430 stainless steel stabilized with niobium produced by direct reduction (just one cold rolling process) to evaluate the effects of grain size on the material deep drawability. Recrystallized samples were heat treated in laboratory to promote the growth of the recrystallized grain. Microstructural characterizations were done by X-ray diffraction for evaluating crystallographic texture, optical microscopy and electron backscatter diffraction (EBSD). The drawability was evaluated by tensile tests for determination of the planar $(\Delta R)$ and normal $(r)$ anisotropy coefficients. An increase in the grain size promoted an increase in the intensity of the Gamma fiber (beneficial) and a reduction in the intensity of the Theta fiber (damaging) on the surface of the material's thickness. At the centerline of the thickness, it was observed that the Gamma fiber's intensity did not change significantly, and that the Theta fiber's intensity was reduced. The change of the crystallographic texture, promoted by the increase of grain size, increased the coefficient of anisotropy $(r)$ in all the analyzed directions and decreased the planar anisotropy coefficient.
\end{abstract}

Keywords: Anisotropy; Texture; Grain size; Deep drawability.

\section{Introduction}

Stainless steels have excellent corrosion resistance and elevated mechanical properties which allow them to be used in several applications in corrosive environments. In the stainless steel family, ferritic stainless steels are used in applications that require high corrosion resistance, good surface quality and good formability [1]

In the 90's, Aperam South America developed a ferritic stainless steel ASTM 430 stabilized with Niobium, aiming to improve its formability [1]. The addition of Niobium inhibits the material recrystallization during the hot rolling process through the precipitation of Niobium carbonitride and the effect of Niobium in solid solution, resulting in a hot rolled coil with a more refined and homogeneous structure, improving the properties of the end product [2].

The stamping performance of ferritic steels is different in comparison to austenitic. During stamping, austenitic steels exhibit good stretching resistance and good strain distribution, allowing manufacturing of complex geometries. Ferritic stainless steels are commonly used for stamping pieces, where the deep drawing processes is predominant [3].

The ferritic stainless steel formability can be evaluated by the Lankford coefficient $r(\alpha)$, which is defined by the ratio of true strain in width and thickness of a specimen during a tensile test in relation to the rolling direction according to an angle $\alpha$. Materials with high average normal anisotropy value, $\bar{r}$, and low planar anisotropy value, $\Delta R$, have a low reduction in their thickness and low strain variation in their plane during the deep drawing process. Features that are advantageous for deep drawing applications $[4,5]$.

In this paper, the influence of the recrystallized grain size of the $430 \mathrm{Nb}$ stainless steel with $0.6 \mathrm{~mm}$ thickness in the evolution of crystallographic texture, anisotropy and, consequently, their formability was evaluated.

\section{Material and methods}

The samples, labeled BF (identification for cold coil sample in portuguese), used in this study were taken out from a cold coil of a Niobium-stabilized ferritic stainless steel AISI $430(430 \mathrm{Nb})$ annealed in an industrial continuous furnace with a heating rate of $24^{\circ} \mathrm{C} . \mathrm{s}^{-1}$ after a cold rolling process with $85 \%$ reduction in thickness. The chemical composition of the samples studied are shown in Table 1.

\subsection{Heat treatment}

The samples were annealed in an industrial furnace according to Table 2. After that, the samples identified as BF-02, BF-03 and BF-04 were submitted to an additional annealing process on a stationary furnace. This second annealing process had the objective to increase the sample recrystallized grain size.

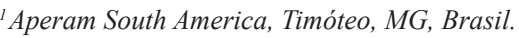

*Corresponding author: caiocesarcaldeiramoura@outlok.com
} 
Table 1. Chemical composition of the $430 \mathrm{Nb}$ samples

\begin{tabular}{ccccccc}
\hline $\mathbf{C}$ & $\mathbf{M n}$ & $\mathbf{S i}$ & $\mathbf{C r}$ & $\mathbf{N}$ & $\mathbf{N i}$ & 0.032 \\
\hline 0.018 & 0.202 & 0.36 & 16.2 & 0.24 & 0.31 & \\
\hline
\end{tabular}

Units in \%mass.

Table 2. Heat treatment of samples

\begin{tabular}{cccc}
\hline Samples & $\mathbf{I T}\left({ }^{\circ} \mathbf{C}\right) \pm \boldsymbol{v a}$ & $\mathbf{A T}\left({ }^{\circ} \mathbf{C}\right) \pm \boldsymbol{v a}$ & $\mathbf{t}(\boldsymbol{s})$ \\
\hline BF-01 & $885 \pm 15$ & - & $15 \pm 1.5$ \\
BF-02 & $885 \pm 15$ & $915 \pm 1$ & $15 \pm 1.5$ \\
BF-03 & $885 \pm 15$ & $965 \pm 1$ & $15 \pm 1.5$ \\
BF-04 & $885 \pm 15$ & $1015 \pm 1$ & $15 \pm 1.5$ \\
\hline
\end{tabular}

$\mathrm{IT}=$ Industrial heat treatment; $\mathrm{AT}=$ Additional heat treatment; $\mathrm{t}=$ Soaking time; $v a=$ Temperature vatiation

\subsection{Microstructure analysis}

Samples were prepared through standard metallographic procedures (cutting, mounting, grinding and mechanical polishing) and analyzed through their longitudinal sections after etching with Villella reagent for $50 \mathrm{~s}$. The average grain size was measured using the Abrams Concentric Circles method according to ASTM E111-13 [6], considering the planar diameter. Six measurements fields along the thickness were made in each sample to measure the grain size and calculate the standard deviation.

\subsection{Texture analysis}

Crystallographic orientation intensity in the surface and center of the samples were analyzed using the X-ray diffraction method with the aid of X'Pert Philips ${ }^{\circledR}$ equipment and the software OIM Analysis ${ }^{\circledR}$, which provided the orientation distribution functions ODFs (Euller angles according to Bunge's convention) for $\ddot{o}_{2}=45^{\circ}$.

\subsection{Mechanical properties}

Tensile tests were carried out, at room temperature, using a traction test machine INSTRON 5583 according to ASTM E8/E8M standard [7]. Sample measurements were made in real time during the tensile test using a displacement point detector. A restricted uniform plastic deformation of $15 \%$ was used to determinate the ' $r$ ', ' $r 45$ ' and 'r90'. Finally, the average normal anisotropy value, $\bar{r}$, was computed using Equation 1.

$$
\frac{\boldsymbol{r}_{0}+2 \boldsymbol{r}_{45}+\boldsymbol{r}_{90}}{4}
$$

where $r_{0}, r_{45}$ and $r_{90}$ correspond to $r(\alpha)$ in the $0^{\circ}, 45^{\circ}, 90^{\circ}$ directions in relation to the rolling direction of the sheet metal, respectively. The planar anisotropy value, $\Delta R$, was evaluated according to Equation 2 [8].

$$
\frac{\boldsymbol{r}_{0}-2 \boldsymbol{r}_{45}+\boldsymbol{r}_{90}}{2}
$$

\section{Results and discussion}

Figure 1a shows the microstructure of a $430 \mathrm{Nb}$ $0.60 \mathrm{~mm}$-thick coil annealed in an industrial continuous furnace. The samples microstructure with an additional heat treatment on a stationary furnace are shown in Figures 1b, 1c, and $1 \mathrm{~d}$. The additional heat treatment process promoted an increase in the average grain size through the migration of the previous grain boundaries in the recrystallized structure [9].

BF-01 and BF-02 samples presented a homogeneous recrystallized ferritic structure along their thickness, precipitates distributed throughout the matrix and $10 \mu \mathrm{m}$ and $12 \mu \mathrm{m}$ grain size, respectively. BF-03 and BF-04 samples presented heterogeneity on structure along their thickness, precipitates distributed throughout the ferritic matrix with $19 \mu \mathrm{m}$ and $28 \mu \mathrm{m}$ grain size, respectively.

The sheet formability can be evaluated through the average normal anisotropy value, $\bar{r}$, and through the low planar anisotropy value, $\Delta R[5,8]$. The average normal anisotropy describes the sheet's ability to resist thickness thinning when subjected to tensile or compressive stresses. While, planar anisotropy describes the strain variation in the sheet plane during the deformation.

During the stamping process, the sheet strain occurs in all directions $\left(0^{\circ}\right.$ to $\left.360^{\circ}\right)$ on the sheet plan. Therefore, rupture occurs in the direction with less thinning resistance. Thus, the analysis of the formability considers $r$ for all directions [1]. Materials with high values of average normal anisotropy and low values of planar anisotropy display better performance in deep drawing process [4].

Table 3 shows that an increase in the grain size from $10 \mu \mathrm{m}$ to $19 \mu \mathrm{m}$ promoted an increase of $r$ in all directions $\left(r_{0}, r_{45}\right.$ and $\left.r_{90}\right)$. However, the increase in the average grain size, from $19 \mu \mathrm{m} 28 \mu \mathrm{m}$, promoted a reduction in $r$ in all directions. Regarding planar anisotropy, the increase in the average grain size, from $10 \mu \mathrm{m}$ to $28 \mu \mathrm{m}$, promoted a reduction in the $\Delta R$ coefficient.

The increase in the $\bar{r}$, i.e, the ability to withstand thinning, is strongly related to the increase in the Gamma fiber components intensity and the reduction of Theta fiber components intensity $[4,8,10,11]$. The increase in the Theta fiber's length reduces the material formability due to the low $r$ of the crystallographic orientations present in this fiber, especially in $r_{45}$ [5].

Figure 2 shows the orientation distribution functions (ODFs) on Bunge convention used to plot the ODFs in figure 3 . The coefficient "s", shown in figure 3 , indicates the measurements positions of the texture along the thickness. Figure 3 shows the crystallographic texture change along the grain growth in the samples. Where, $s=0$ indicates the 
a) $\mathrm{BF}-01[10 \mu \mathrm{m}] \mid \mathrm{SD}=0.33 \mu \mathrm{m}$

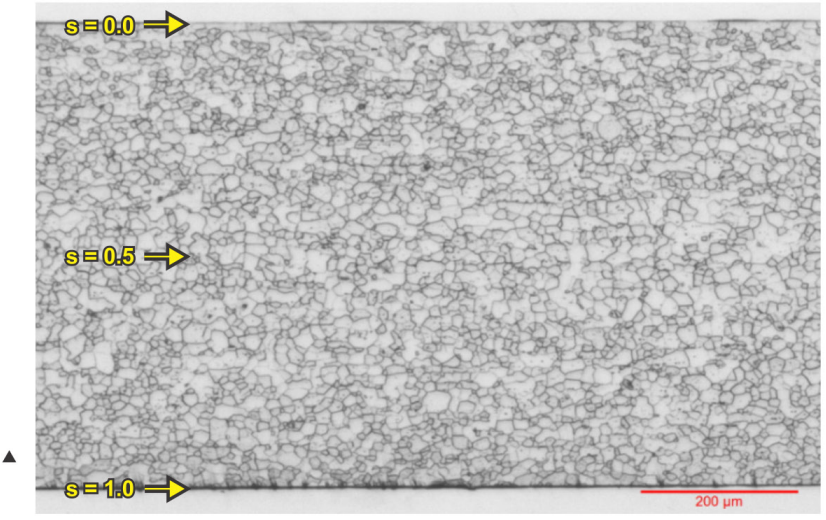

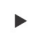

c) $B F-03[19 \mu \mathrm{m}] \mid \mathrm{SD}=0.38 \mu \mathrm{m}$

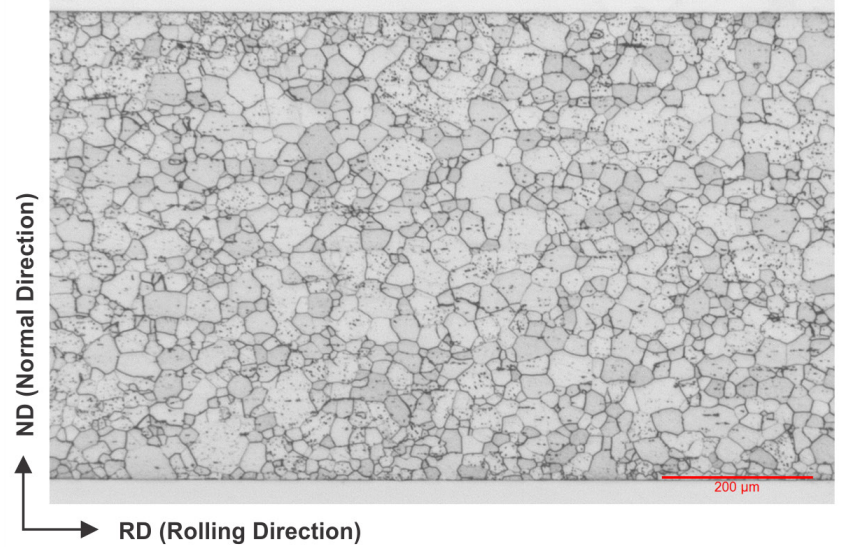

b) $B F-02[12 \mu \mathrm{m}] \mid \mathrm{SD}=0.27 \mu \mathrm{m}$

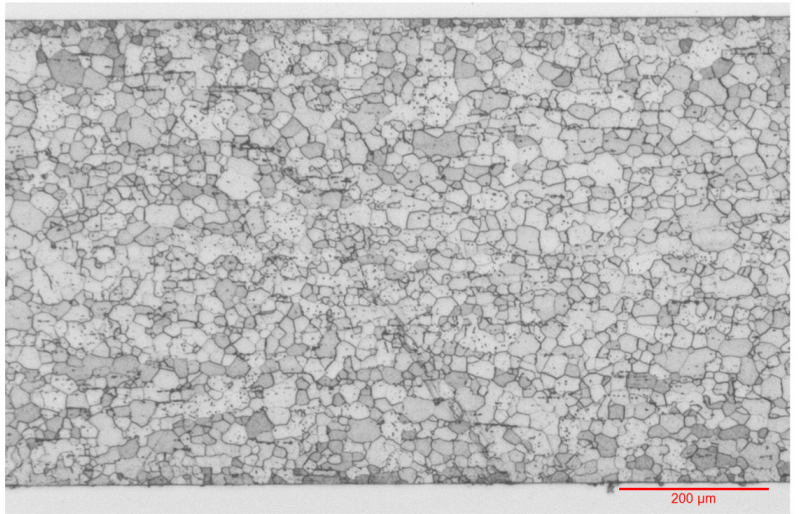

d) $B F-04[28 \mu \mathrm{m}] \mid \mathrm{SD}=0.23 \mu \mathrm{m}$

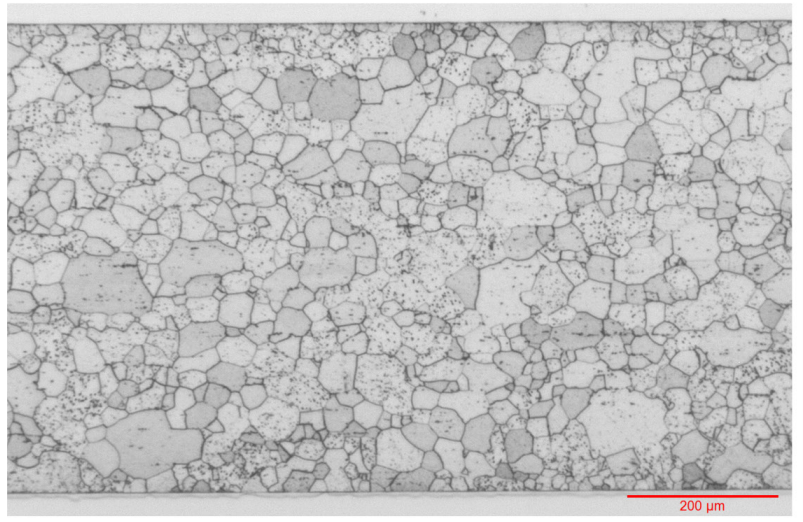

Figure 1. Microstructure in $200 \mu \mathrm{m}$ (red bar) and average grain size of $430 \mathrm{Nb}$ samples after the heat treatment. (a) No additional heat treatment; (b) with additional heat treatment of $915^{\circ} \mathrm{C}$; (c) with additional heat treatment of $965^{\circ} \mathrm{C}$; and (d) with additional heat treatment of $1015^{\circ} \mathrm{C}(s=0$ for surface layer and $s=0.5$ for center layer). SD It is an abbreviation for standard deviations.

Table 3. Mechanical properties of samples

\begin{tabular}{cccccc}
\hline Samples & $\boldsymbol{r 0}^{\circ}$ & $\boldsymbol{r 4 5}^{\circ}$ & $\boldsymbol{r 9 0}^{\circ}$ & $\overline{\boldsymbol{r}}$ & \multicolumn{1}{c}{$\boldsymbol{R}$} \\
\hline $\mathrm{BF} 01-10 \mu \mathrm{m}$ & 1.59 & 1.10 & 1.96 & 1.64 & 0.68 \\
$\mathrm{BF} 02-12 \mu \mathrm{m}$ & 1.64 & 1.33 & 2.31 & 1.98 & 0.65 \\
$\mathrm{BF} 03-19 \mu \mathrm{m}$ & 1.80 & 1.70 & 2.73 & 1.74 & 0.57 \\
$\mathrm{BF} 04-28 \mu \mathrm{m}$ & 1.42 & 1.66 & 2.23 & & 0.16 \\
\hline
\end{tabular}

$\Delta R=$ Planar anisotropy; [\%]; $\bar{r}=$ Average normal anisotropy.

ODF on surface of sample thickness and $\mathrm{s}=0.5$ indicates the ODF in center of thickness.

In general, all samples (Figure 3) exhibited a recrystallization texture in the (334) [4 $\overline{8} 3]$ component, which is typical of a cold rolled ferritic stainless steel subjected to direct rolling process $[5,8]$. This texture can be explained by the preferential growth of the component (334)[483] around the rolled component (112)[110] of the $\alpha$ fiber, due to the oriented growth mechanism caused by the selective drag of segregated particles in the grain boundaries $[8,10]$. The other higher intensity was found at (111)[112]. Both components, (334)[4833] and (111)[112] belong to the gamma fiber.

Table 4 and Table 5 show the evolution of the principal volumetric fraction texture of the samples for each grain size on surface $(\mathrm{s}=0)$ and center $(\mathrm{s}=0.5)$. Figure 3 and Figure 4 show the texture evolution throughout the ODFs. It can be observed on the surface of the thickness (Table 4) that an increase in the average grain size, from $10 \mu \mathrm{m}$ to $19 \mu \mathrm{m}$, promoted a reduce on volume fraction of Theta fiber $(100)[u v w]$ and an increase on volume fraction of fiber $\gamma$ components $(111)[1 \overline{2} 1]$ and (111)[112]. Simultaneously, at the center of the thickness (Table 5), $\gamma$ fiber remained stable and the Theta fiber fraction (100) $[u v w]$ was reduced with increased average grain size from $10 \mu \mathrm{m}$ to $28 \mu \mathrm{m}$.

That the obtained values of $\bar{r}$ (Table 3 ) showed good correlation with the surface Gamma/Theta ratio values (Table 4). By increasing the grain size from $10 \mu \mathrm{m}$ to $19 \mu \mathrm{m}, \bar{r}$ was increased from 1.44 to 1.98 and the Gamma/Theta ratio on surface was increased from 4.36 to 4.83 . By further increasing 


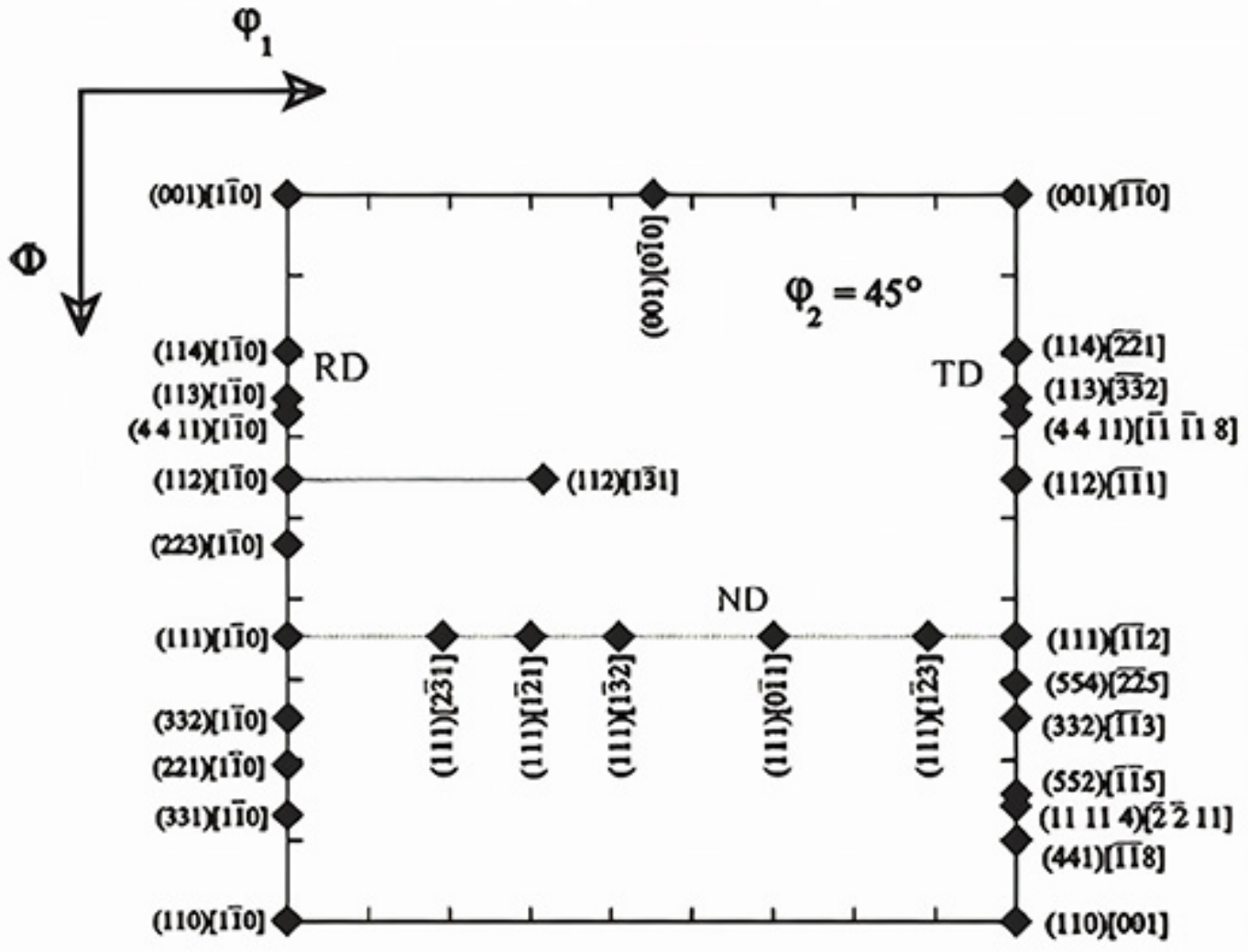

Figure 2. Section for $\delta_{2}=45^{\circ}$ showing the position of main orientations along with the RD, TD: transverse direction and ND. Euler angles on notations proposed by Bunge [12]

a) $\mathrm{S}=\mathbf{0}$

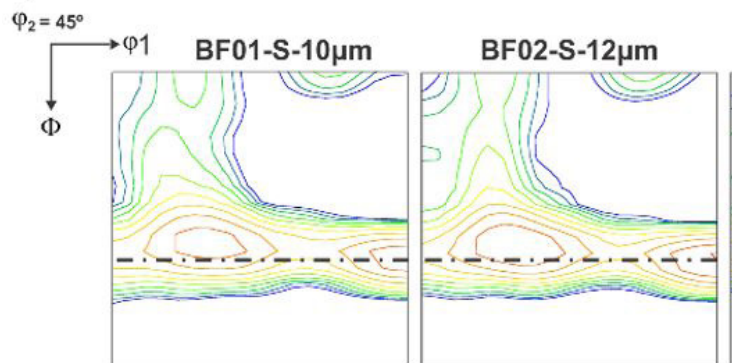

MI: 12.020

MI: 13.860

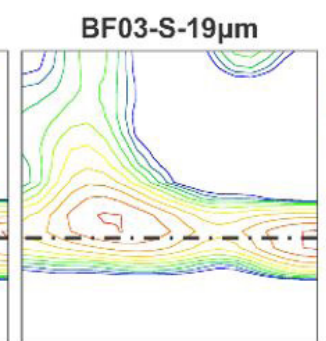

MI: 14.750

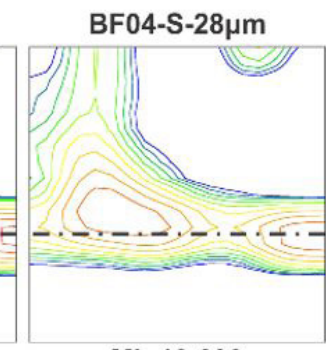

MI: 13.600

b) $\mathrm{S}=0.5$

$$
\varphi_{2}=45^{\circ}
$$

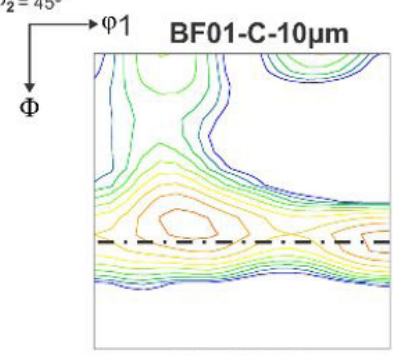

MI: 11.680

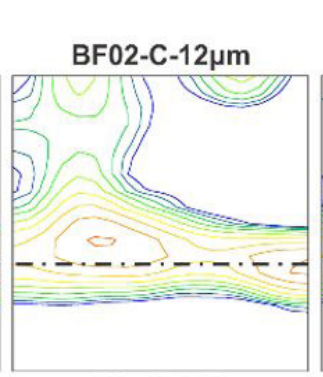

MI: $\mathbf{1 0 . 9 5 0}$

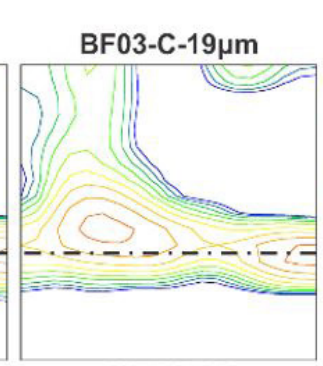

MI: 11.710

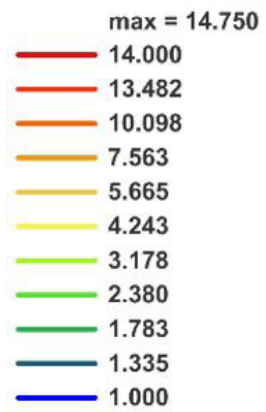

MI = Maximum Intensity

Figure 3. Recrystallization textures of the samples, where (a) $s=0$ (BFXX-S) represents the surface layer and (b) $s=0.5$ (BFXX-C) represents the center layer. 
Table 4. Volumetric fractions [\%] and Gamma/Theta ratios of surface samples

\begin{tabular}{|c|c|c|c|c|}
\hline Sample & Rotated Cube (001)[110] & Theta (100)[uvw] & Gamma (111)//ND & Gamma/Theta \\
\hline BF01-S-10 $\mu \mathrm{m}$ & 2.82 & 9.29 & 40.28 & 4.36 \\
\hline BF02-S-12 $\mu \mathrm{m}$ & 2.60 & 9.09 & 41.42 & 4.56 \\
\hline BF03-S-19 $\mu \mathrm{m}$ & 1.66 & 7.43 & 43.31 & 5.83 \\
\hline BF04-S-28 $\mu \mathrm{m}$ & 1.38 & 7.63 & 41.66 & 5.46 \\
\hline
\end{tabular}

$\mathrm{ND}=$ Normal Direction.

Table 5. Volumetric fractions [\%] and Gamma/Theta ratios of center samples

\begin{tabular}{|c|c|c|c|c|}
\hline Sample & Rotated Cube (001)[110] & Theta (100)[uvw] & Gamma (111)//ND & Gamma/Theta \\
\hline BF01-C-10 $\mu \mathrm{m}$ & 2.83 & 9.56 & 40.11 & 4.20 \\
\hline BF02-C-12 $\mu \mathrm{m}$ & 2.90 & 10.09 & 39.40 & 4.90 \\
\hline 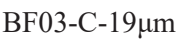 & 2.10 & 8.76 & 40.42 & 4.62 \\
\hline 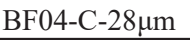 & 1.40 & 8.27 & 39.68 & 4.81 \\
\hline
\end{tabular}

$\mathrm{ND}=$ Normal Direction.

a) $\mathrm{S}=0$ (SURFACE)
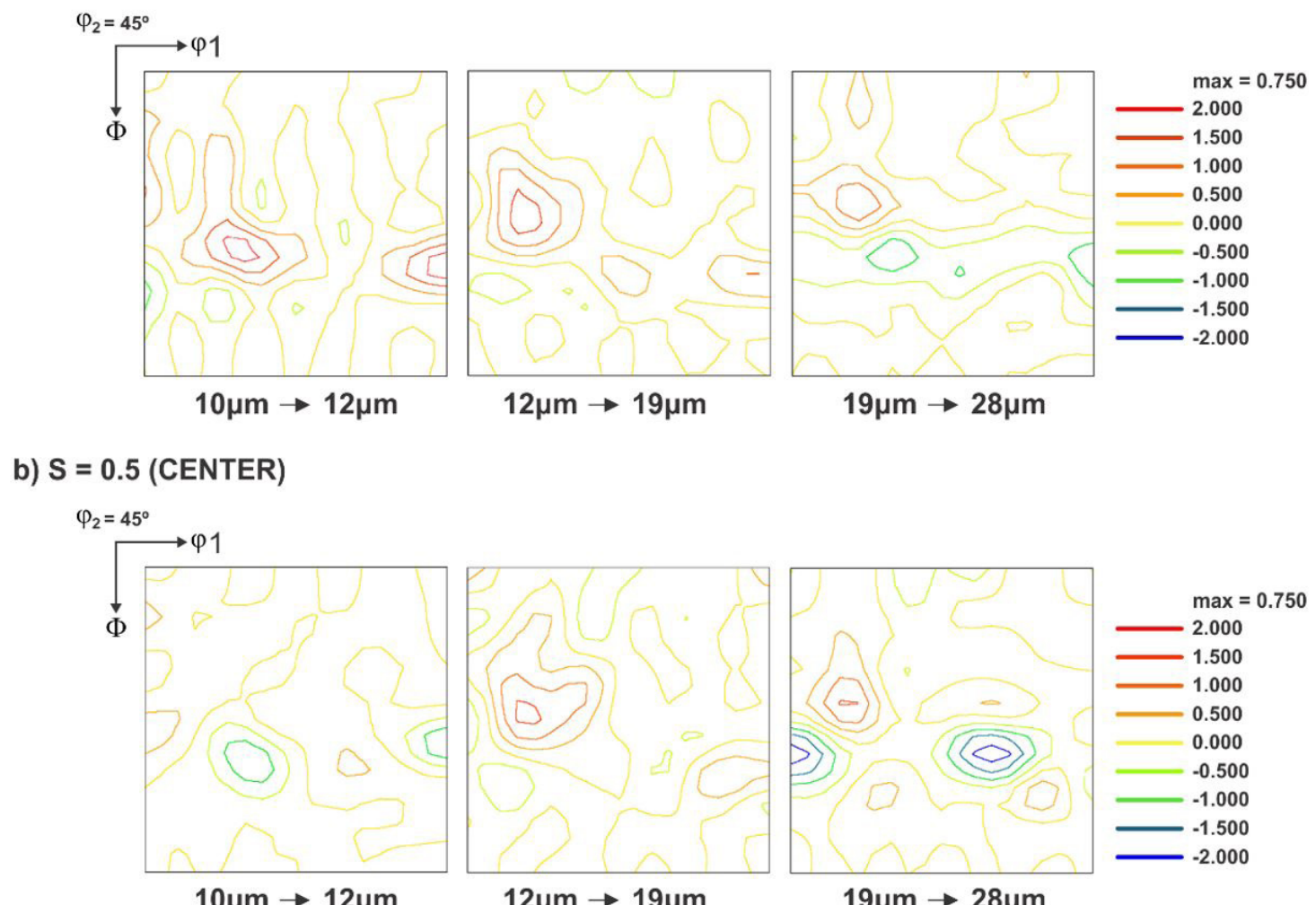

Figure 4. Texture change shown by subtraction of ODFs samples in function of grain growth. where (a) $s=0$ represents the surface layer and (b) $s=0.5$ represents the center layer.

the grain size from $19 \mu \mathrm{m}$ to $28 \mu \mathrm{m}, \bar{r}$ was reduced to 1.74 and the Gamma/Theta ratio on surface was reduced to 5.46.

Regarding planar anisotropy, the $\Delta R$ was reduced from 0.68 to 0.16 due to the grain growth from $10 \mu \mathrm{m}$ to $28 \mu \mathrm{m}$. This effect occurred due to the reduction of Rotated Cube $(001)[1 \overline{1} 0]$ and Theta fiber volumetric fractions improving the steel formability [5].Figure 4 shows the texture change calculated by subtraction of ODFs samples, where each figure shows the texture differential between the grain sizes. Positive values indicate an increase in components intensity, while the negative values indicate a reduction on components intensity.

Figure $4 \mathrm{a}$ and $4 \mathrm{~b}$ shows that, grain growth from $10 \mu \mathrm{m}$ to $19 \mu \mathrm{m}$, the $\gamma$ fiber was intensified on surface and center 
of thickness. On grain growth from $19 \mu \mathrm{m}$ to $28 \mu \mathrm{m} \gamma$ fiber intensity was decreased on surface and center of thickness.

The grain growth from $10 \mu \mathrm{m}$ to $19 \mu \mathrm{m}$ was able to promote a formability accretion through $\gamma$ fiber increase and, consequently, $\bar{r}$ increase. Therefore, the formability reduction that occurred in grain growth from $19 \mu \mathrm{m}$ to $28 \mu \mathrm{m}$ was caused by selective drag effect by the segregated particles present in the grain boundaries $[8,10]$. This mechanism intensified

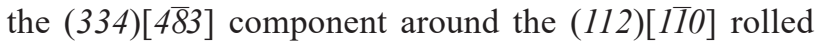
component of the $\alpha$ fiber and reduced the $\gamma$-fiber intensity.

\section{Conclusions}

Four $430 \mathrm{Nb}$ stainless steels samples with a thickness of $0.6 \mathrm{~mm}$ and from the same coil were submitted to an additional annealing process on a stationary furnace using different temperatures. The influence of the grain size on their formability was observed and the effect of the main texture components on the resulting $\bar{r}$ - values was analyzed. It was concluded that the formability can be improved through grain growth. Increasing the grain size from $10 \mu \mathrm{m}$ to $19 \mu \mathrm{m}$, the $\bar{r}$ was increased from 1.44 to 1.98 . However, from $19 \mu \mathrm{m}$ average grain size, the drag effect spins the $\gamma$

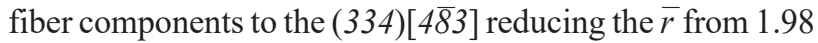
to 1.74 and, consequently reducing the material formability.

\section{Acknowledgements}

The authors gratefully acknowledge financial and technical support from Aperam South America and Centro Universitário Católico do Leste de Minas Gerais (Unileste).

\section{References}

1 Oliveira TR, Alves HJ, Lopes RG, Guida RB. Influência da textura e da microestrutura na estampabilidade dos aços inoxidáveis ferríticos 430 estabilizados ao nióbio. In: Anais do $63^{\circ}$ Congresso da Associação Brasileira de Materiais; 2008; Santos. São Paulo: ABM Brasil; 2008.

2 Oliveira TR. Effet du niobium et du titane sur la déformation à chaud d'aciers inoxydables ferritiques stabilisés [tese]. Saint-Étienne: Escole de Mines de Saint-Étienne; 2003.

3 Oliveira TR, Silva RC, Alcântara CM, Lopes RG, Ferreira JS, Arthuso EM, et al. Aço inoxidável ferrítico tipo ASTM 430 para estampagem profunda, com alto brilho e isento de estriamento. In: Anais do $68^{\circ}$ Congresso Anual da Associação Brasileira de Materiais; 2013; São Paulo. São Paulo: ABM Brasil; 2013.

4 Yazawa Y, Osaki Y, Kato Y, Furukimi O. Development of ferritic stainless steel sheets with excellent deep drawability by $\{111\}$ recrystallization texture control. JSAE Review. 2003;24(4):483-488.

5 Lee KM, Engler O, Huh MY. Effect of texture components on the Lankford parameters in ferritic stainless steel sheets. ISIJ International. 2011;53(3):522-529.

6 American Society for Testing and Materials. ASTM E112-13: standard tests methods for determining average grain size. West Conshohocken: ASTM; 2013.

7 American Society for Testing and Materials. ASTM E8/E8M-16a: standard test methods for tension testing of metallic materials. West Conshohocken: ASTM; 2016.

8 Jaskarin M, Jarvenpaa A, Karjalainen P. The effect of heating rate on texture and formability of Ti-Nb stabilized ferritic stainless steel. Key Engineering Materials. 2018;786:3-9.

9 Padilha A, Siciliano F. Encruamento, rescristalização, crescimento de grão e textura. 3. ed. São Paulo: Associação Brasileira de Materiais; 2005.

10 Raabe D, Lucke K. Selective particle drag during primary recrystallization of Fe-Cr alloys. Scripta Metallurgica et Materialia. 1992;26(1):19-24.

11 Tanure L, Alcantara M, Oliveira T, Santos D, Gonzalez B. Microstructure, texture and microhardness evolution during annealing heat treatment and mechanical behavior of the niobium-stabilized ferritic stainless steel ASTM 430 and noibium-titanium-stabilized ferritic stainless steel ASTM 439: a comparative study. Materials Research. 2017;20(6):1650-1657.

12 Abreu HF, Bruno AD, Tavares SS, Santos RP, Carvalho SS. Effect of High temperature annealing on texture and microstructure on an AISI-444 ferritic stainless steel. Materials Characterization. 2006;57(4-5):342-347.

Received: 15 Oct. 2019

Accepted: 9 Jun. 2020 